\title{
Is Iron Deficiency Anaemia, a risk Factor For Wheeze Associated Respiratory Tract Infection in Children?
}

\author{
Agrawal $A^{1}$, Gupta $R^{2}$, Sodhi KDㄹ ${ }^{3}$ Raghav $V^{4}$
}

\begin{abstract}
Introduction: Wheezing is the common in children with cumulative prevalence of almost $50 \%$ by the age of 6 yrs. Iron deficiency anaemia is an independent risk factor for lower respiratory tract infections (LRTI), however may also play an important role in wheeze associated respiratory tract infection. The present study aimed at finding a correlation between iron deficiency anaemia and wheeze associated respiratory tract infection. Materials and Methods: This case control study was conducted at a multidisciplinary tertiary care hospital from Jul 2012 to Jun 2013 among children six months to five years and having $\geq 2$ episodes of wheeze associated respiratory tract infections. The clinical presentation and laboratory profile were recorded on a predesigned performa. Iron deficiency anaemia was diagnosed by haemoglobin $<11.0 \mathrm{gm} \%$, serum ferritin $<12 \mathrm{ng} / \mathrm{ml}$ and $\mathrm{RDW}>15 \%$. The statistical analysis was done using SPSS, Version 15.0. Results: A total of 100 children were enrolled in the study, of which 50 cases and 50 matched controls. Majority of subjects in both groups were males $(n=31 ; 62 \%)$, with male to female ratio of $1.6: 1$. Proportion of cases with iron deficiency anaemia were higher among cases(32\%) as compared to controls(24\%) but the difference between two groups was not significant statistically $(p=0.373)$ despite having higher risk(OR=1.49;95\% $\mathrm{Cl}=0.62-3.59)$. Mean monocyte, oeosinophil and absolute oeosinophil count was found to be significantly higher in cases as compared to controls $(p<0.05)$. Conclusion: The present study do not suggest a possible linkage between iron deficiency anemia and wheeze associated respiratory infection, however its role as causative factor needs to be explored through long-term prospective and intervention studies on a large population.
\end{abstract}

Key words: Iron deficiency anaemia, Wheeze associated respiratory infection,

\section{Introduction}

$\mathrm{P}$ opulation studies have shown that approximately one in three children has at least one episode of wheezing prior to their third birthday, and the cumulative prevalence of wheeze is almost $50 \%$ at the age of six years ${ }^{1}$. Despite its high prevalence, there is a lack of evidence regarding the pathophysiology and treatment of
'Dr. Anupama Agrawal, MBBS, MD, Resident in Paediatrics, Command Hospital (CC) Lucknow, ${ }^{2}$ Col Rakesh Gupta, MBBS, MD, Professor \& Head of department (Paediatrics), Command Hospital (CC) Lucknow, ${ }^{3}$ Col K D Sodhi, MBBS, MD, Professor \& Head of department (Paediatrics), Command Hospital (WC) Chandigarh, "Brig Vinod Raghav, MBBS, MD, Dy Commandant \& Consultant Pathology, Command Hospital (CC) Lucknow, UP, India.

Address for correspondence:

Col Rakesh Gupta, Professor of Paediatrics

Department of Paediatrics, Command

Hospital(CC)

Lucknow Cantt-226002 (UP), India

Tel No; +919935842002, +919850042002,

E-mail:colrgupta@gmail.com

\section{How to cite}

Agrawal A, Gupta R, Sodhi KD, Raghav V. Is Iron Deficiency Anaemia, a risk Factor For Wheeze Associated Respiratory Tract Infection in Children? J Nepal Paediatr Soc 2014;34(3):195-199.

doi: http://dx.doi.org/10.3126/jnps.v34i3.11378

This work is licensed under a Creative Commons Attribution 3.0 License.

\section{(c) (i)}

first episode of wheeze ${ }^{1}$. WHO estimates that in 2001, iron deficiency anaemia (IDA) resulted in 273,000 deaths: $45 \%$ in Southeast Asia. $^{2}$ Iron deficiency exerts adverse effects on immune response and alters the metabolism and growth of pathogens. It acts as an independent risk factor for developing lower respiratory tract infections (LRTI) in children ${ }^{3}$. Iron deficiency thus may play an important role in wheeze associated respiratory tract infection. With 
this background the present study was carried out to evaluate the role of iron deficiency anaemia as a risk factor for wheeze associated respiratory tract infection.

\section{Material and Methods}

This case control study was conducted at a multidisciplinary tertiary care hospital from July 2012 to June 2013. Children in the age group six months to five years and having two or more episodes of wheeze associated respiratory tract infections, reporting to paediatrics department were enrolled as cases and healthy children of the same age group as controls. Children with co-morbidities like pre-existing pulmonary, cardiac or any other systemic illness and congenital anomalies were excluded from study.

The clinical presentation of the patients was recorded after taking a detailed history from parents. Clinical signs and laboratory investigations were recorded on a predesigned performa. Healthy controls were selected from the paediatric OPD and well baby clinic after taking consent from parents. Ethical clearance was obtained from institutional ethical committee. A sample size of 50 children was selected for each group of cases and control. Venous blood was collected from each participant for complete haemogram, peripheral bloods smear and iron studies. Iron deficiency was diagnosed by haemoglobin value $<11.0 \mathrm{gm} \%$, serum ferritin $<12 \mathrm{ng} / \mathrm{ml}$ and RDW $>15 \%$. The statistical analysis was done using SPSS (Statistical Package for Social Sciences) Version 15.0 statistical Analysis Software.

\section{Results}

A total of 50 children in each group were enrolled in the study. Majority of subjects in both the groups were males $(n=31 ; 62 \%)$. Male to female ratio of study subjects was 1.63:1. Mean age of cases was $2.49 \pm 0.88$ years (range $0.6-4.0$ years) whereas in control was $2.62 \pm 0.83$ years (range $1-4.5$ years). There was no significant difference between two groups with respect to gestational age at delivery, mode of delivery, need of NICU admission and use of drugs in neonatal period $(p>0.05)$. Both the groups were matched for anthropometric parameters and immunization status. The demographic characteristics of study population are shown in table 1 and fig 1.

On clinical evaluation of the cases, pallor was observed in 28 (56\%) cases, mild to moderate respiratory distress was observed in 13 (26\%), chest retractions in 11 (22\%), audible wheeze on inspiration in $5(10 \%)$, presence of rhonchi in $3(6 \%)$, hyper resonant note on percussion in $8 \%$ and bilateral wheeze in 46 (92\%) cases.

The haematological parameters were similar in two groups, except for difference in monocyte and oeosinophil counts and absolute oeosinophil count. Mean monocyte, oeosinophil and absolute oeosinophil count was found to be significantly higher in cases as compared to controls $(p<0.05)$. Though proportion of cases with iron deficiency anaemia was higher among cases $(32 \%)$ as compared to controls (24\%) yet the difference between two groups was not significant statistically ( $p=0.373$ ) as seen in table 3 \& fig -2

The peripheral blood smear was evaluated and microcytic, hypochromic blood picture was slightly higher in cases, but statistically, there was no significant difference between two groups $(p>0.05)$. The comparison of blood picture is shown in table 4 .

Table 1: Demographic Characteristics of cases and controls

\begin{tabular}{|c|c|c|c|c|c|c|c|}
\hline \multirow{2}{*}{ SN } & \multirow{2}{*}{ Characteristic } & \multicolumn{2}{|c|}{ Cases $(n=50)$} & \multicolumn{2}{|c|}{ Controls $(n=50)$} & \multicolumn{2}{|c|}{ Statistical Significance } \\
\hline & & No. & $\%$ & No. & $\%$ & $\chi^{2}$ & $\mathbf{p}$ \\
\hline \multirow[t]{3}{*}{1.} & Gender & & & & & & \\
\hline & Male & 31 & 62 & 31 & 62 & \multirow{2}{*}{0} & \multirow{2}{*}{1} \\
\hline & Female & 19 & 38 & 19 & 38 & & \\
\hline 2. & Mean Age $\pm S D$ (range) in years & \multicolumn{2}{|c|}{$2.49 \pm 0.88(0.6-4.0)$} & \multicolumn{2}{|c|}{$2.62 \pm 0.83(1-4.5)$} & \multicolumn{2}{|c|}{$\mathrm{t}=-0.778 ; p=0.439$} \\
\hline \multirow[t]{3}{*}{3.} & \multicolumn{7}{|l|}{ Place of living } \\
\hline & Rural & 22 & 44 & 21 & 42 & \multirow{2}{*}{0.041} & \multirow{2}{*}{0.840} \\
\hline & Urban & 28 & 56 & 29 & 58 & & \\
\hline
\end{tabular}


Table 2: Comparison of haematological parameters in study population

\begin{tabular}{|c|c|c|c|c|c|c|c|}
\hline \multirow{2}{*}{ SN } & \multirow{2}{*}{ Features } & \multicolumn{2}{|c|}{ Cases $(n=50)$} & \multicolumn{2}{|c|}{ Controls $(n=50)$} & \multicolumn{2}{|c|}{ Statistical Significance } \\
\hline & & Mean & SD & Mean & SD & "t" & $p$ \\
\hline 1. & $\mathrm{Hb}(\mathrm{g} \%)$ & 10.52 & 1.67 & 10.47 & 1.57 & 0.142 & 0.888 \\
\hline 2. & TLC (’000) & 10.1 & 3.4 & 9.6 & 3.0 & 0.783 & 0.436 \\
\hline 3. & Polymorphs (\%) & 46.16 & 13.02 & 48.84 & 11.04 & -1.110 & 0.270 \\
\hline 4. & Lymphocytes (\%) & 40.34 & 12.71 & 42.60 & 9.38 & -1.012 & 0.314 \\
\hline 5. & Monocytes (\%) & 2.98 & 2.00 & 2.16 & 1.15 & 2.509 & 0.014 \\
\hline 6. & Eosinophils (\%) & 4.82 & 4.52 & 2.74 & 2.13 & 2.944 & 0.004 \\
\hline 7. & Absolute eosinophil count & 621.58 & 298.46 & 444.40 & 176.52 & 3.613 & $<0.001$ \\
\hline 8. & RDW (\%) & 15.05 & 1.72 & 14.67 & 1.59 & 1.156 & 0.251 \\
\hline 9. & TIBC $(\mu \mathrm{g} / \mathrm{dl})$ & 350.50 & 59.38 & 340.16 & 49.21 & 0.948 & 0.345 \\
\hline 10. & S. Iron ( $\mu \mathrm{g} / \mathrm{dl})$ & 94.48 & 40.22 & 101.12 & 32.98 & -0.902 & 0.369 \\
\hline 11. & S.transferrin saturation (\%) & 32.43 & 15.00 & 34.24 & 11.94 & -0.668 & 0.505 \\
\hline 12. & S. Ferritin (ng/ml) & 29.94 & 22.42 & 34.42 & 18.79 & -1.084 & 0.281 \\
\hline
\end{tabular}

Table 3: Comparison of iron deficiency anaemia in study population

\begin{tabular}{|c|l|c|c|c|c|}
\hline \multirow{2}{*}{ SN } & \multirow{2}{*}{ Iron Deficiency Anaemia } & \multicolumn{2}{|c|}{ Cases $(\mathbf{n = 5 0})$} & \multicolumn{3}{|c|}{ Controls $(\mathbf{n}=\mathbf{5 0})$} \\
\cline { 3 - 7 } & & No. & $\%$ & No. & $\%$ \\
\hline 1. & Absent & 34 & 68 & 38 & 76 \\
\hline 2. & Present & 16 & 32 & 12 & 24 \\
\hline
\end{tabular}

$\chi^{2}=0.794(d f=1) ; p=0.373$

$\mathrm{OR}=1.49 ; 95 \% \mathrm{Cl}=0.62-3.59$ ).

Table 4: Comparison of blood picture in study population

\begin{tabular}{|c|l|c|c|c|c|}
\hline \multirow{2}{*}{ SN } & \multirow{2}{*}{ PBS } & \multicolumn{2}{|c|}{ Cases $(\mathbf{n = 5 0})$} & \multicolumn{2}{c|}{ Controls $(\mathbf{n}=\mathbf{5 0})$} \\
\cline { 3 - 6 } & & No. & $\mathbf{\%}$ & No. & \% \\
\hline 1. & Microcytic Hypochromic & 20 & 40 & 17 & 34 \\
\hline 2. & Microcytic hypochromic picture with leucocytosis & 2 & 4 & 0 & 0 \\
\hline 3. & Microcytic hypochromic with eosinophilia & 2 & 4 & 0 & 0 \\
\hline 4. & Normocytic Normochromic & 26 & 52 & 33 & 66 \\
\hline
\end{tabular}

$\chi 2=5.074(d f=3) ; p=0.166$

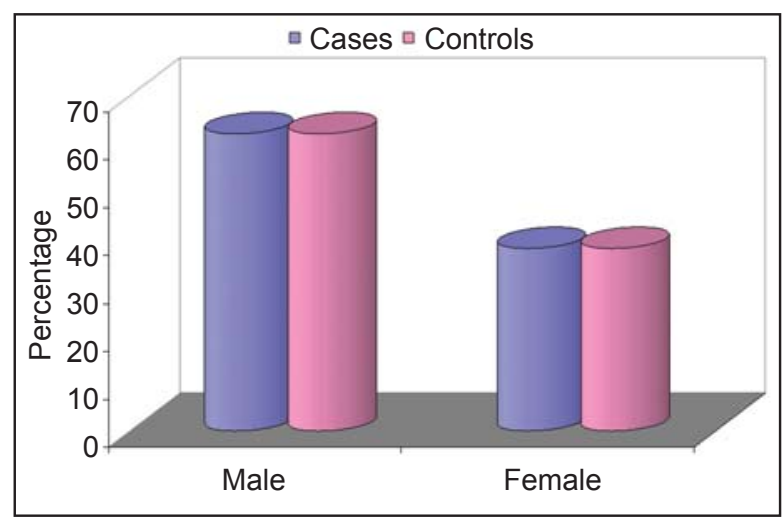

Fig 1: Sex distribution of study population

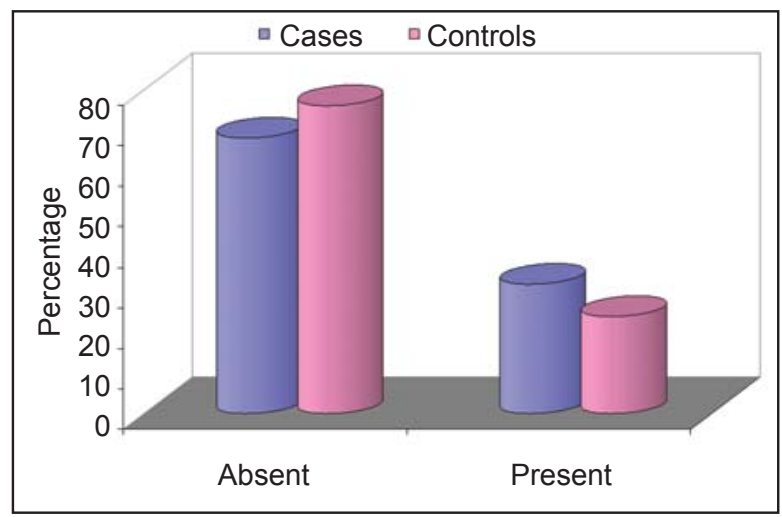

Fig 2: Comparison of indices of iron deficiency anaemia in study population 


\section{Discussion}

IDA is a problem of public health magnitude in preschool children in India. In communities subsisting on plant-based diets, inadequate dietary intake of iron with particular reference to bioavailable iron accounts for the problem of IDA. Infectious illnesses are known to contribute to various nutritional deficiencies through their physiologic and metabolic effects. Among preschool children living in underprivileged communities in developing countries, respiratory infectious diseases and IDA are often coexistent and have complex, mutually adverse interactions leaving severe functional consequences.

In present study, there were more number of boys $31(62 \%)$ having wheeze associated respiratory infection and were in agreement with the observations made by several researchers ${ }^{4}$ who showed higher prevalence of males in different subsets of children suffering from respiratory tract infections including those categorized as wheeze-associated infections. The mean age of patients was $2.49 \pm 0.88$ years with maximum age of 4 years, thus indicating higher prevalence of wheezeassociated respiratory illnesses among younger age group. The Tucson Children's Respiratory Study (TCRS) corroborates the findings of the present study.

The acute illness may also affect the haematological parameters. A prospective study done on children with acute respiratory infections, a significant drop in haemoglobin concentration by days 9 to 14 post mild viral illness was seen ${ }^{6}$. Serum iron and transferrin saturation fell significantly, whereas erythrocyte protoporphyrin and serum ferritin increased significantly. Most of the changes in iron parameters persisted for two or three weeks after the appearance of fever, and some measures may have even become abnormal during the incubation period of viral illness. Thus as infection or inflammation can influence iron status, it is always very challenging to exclude iron deficiency anaemia in the context of concomitant inflammation?. That is why in present study we used combined criteria (serum ferritin and RDW) as the criteria for evaluation of iron deficiency.

In the present study, taking haemoglobin levels as the criteria for detecting anaemia majority (57\%) were found to be anaemic and among these 28 (49.1\%) were found to be having iron deficiency. Thus, in present study the prevalence of iron deficiency anaemia itself is lower than that reported in general $(67-77 \%)^{8}$ which might be due to usage of a strict criteria of combination of serum ferritin $<12 \mathrm{ng} / \mathrm{ml}$ and RDW $>15 \%$. As aforementioned, the combined criteria is more specific and rules out the chance higher prevalence of IDA $^{9}$. Prevalence of iron deficiency anaemia as per our criteria in present study was $32 \%$ in cases and $24 \%$ in control group, however, the difference was not significant statistically though children with iron deficiency anaemia were at a higher risk of wheeze associated respiratory diseases ( $O R=1.49$; $95 \% \mathrm{Cl} 0.62-3.59)$. This finding is in agreement with the observations of workers such as Ramakrishnan and Borade in 2010, who reported higher prevalence of asthma among anaemic children as compared to non-anaemic children and also indicated a significant association between iron-deficiency anaemia and respiratory illness ${ }^{10}$.

On evaluating the haematological profile for differential counts of the children in case group to that of control group, no statistically significant difference was observed between two groups except of mean monocyte, oeosinophil and absolute oeosinophil count to be higher in cases as compared to controls and may indicate the presence of an atopic aetiology in wheezeassociated infections. The limitation of the study was a smaller sample size and possible linkage may be further investigated on a larger sample size

\section{Conclusion}

The findings in present study do not suggest a possible linkage between iron deficiency anaemia and wheeze associated respiratory infection. However, investigation of a link is a step forward in direction of further studies specifically targeted to review the role of iron deficiency anaemia as a cause of wheeze associated respiratory infection. Given the high prevalence of iron deficiency anaemia in Indian population, it is essential that possibility of such linkage should be explored further in long-term prospective intervention studies on a larger population to establish the iron deficiency anaemia as a cause of wheeze associated respiratory infection.

Acknowledgements: Nil.

Funding: Nil

Conflict of interests: None

Permission from IRB: Yes

\section{References}

1. John BM, Singh D. Comparison of Nebulised Salbutamol and L-epinephrine In First Time Wheezy Children. MJAFI 2010;66(1):9-13.

2. WHO / UNICEF / UNU. Iron-deficiency anemia: Assessment, prevention and control: A guide for 
programme managers. Geneva: World Health Organization; 2001.

3. Savitha MR, Nandeeshwara SB, Pradeep Kumar MJ, ul-Haque F, Raju CK. Modifiable risk factors for acute lower respiratory tract infections. Indian J Pediatr 2007;74(5):477-82.

4. Bosken $\mathrm{CH}$, Hunt WC, Lambert WE, Samet JM. A Parental history of asthma is a risk factor for wheezing and nonwheezing respiratory illnesses in infants younger than 18 months of age. Am J Respir Crit Care Med 2000;161(6):1810-815.

5. Taussig LM, Wright AL, Holberg CJ, Halonen M, Morgan WJ, Martinez FD. Tucson children's respiratory study: 1980 to present. J Allergy Clin Immunol 2003;111(4):661-75.
6. Ballin A, Senecky $Y$, Rubinstein $U$, et al. Anemia associated with acute infection in children. Isr Med Assoc J 2012;14(8):484-87.

7. Skikne BS. Serum Transferrin receptor. Am J Hematol 2008;83(11):872-75.

8. Zhu A, Kaneshiro M, Kaunitz JD. Evaluation and Treatment of Iron Deficiency Anemia: A Gastroenterological Perspective. Dig Dis Sci 2010;55(3):548-59.

9. Bhaskaran P, Madhavan NK, Balakrishnan N. Serum transferrin receptors in children with respiratory infections. Eur J Nutr 2003;57(1):75-80.

10. Ramakrishnan K, Borade A. Anemia as a risk factor for childhood asthma. Lung India 2010;27(10):513. 